\title{
Hyponatraemia in a woman with a pelvic mass
}

\section{K M Chow, C C Szeto}

Answers on $p 63$.

A 57 year old Chinese woman was admitted with a bulky, right lower abdominal mass. She was known to have end stage renal disease and had received a cadaveric renal transplant eight years previously. Further investigation with imaging confirmed an irregular, soft tissue mass in the right iliac and pelvic region with mass effect compressing on the ureter of the graft kidney. There was significant hypercalcaemia with a serum calcium level of 3.02 $\mathrm{mmol} / \mathrm{l}$ (normal range $2.20-2.62 \mathrm{mmol} /$ 1). The serum sodium and creatinine levels were 135 mmol/l (normal range 134$145 \mathrm{mmol} / \mathrm{l}$ ) and $141 \mathrm{\mu mol} / \mathrm{l}$ (normal range 44-107 $\mu \mathrm{mol} / \mathrm{l})$, respectively. A biopsy of the pelvic mass showed a posttransplant lymphoproliferative disorder
Chemotherapy was started in view of the extensive disease involvement. Treatment consisted of doxorubicin, cyclophosphamide, vincristine, and prednisolone (CHOP) after saline fluid administration. The patient tolerated the chemotherapy well without development of acute tumour lysis. Clinical response was achieved, as indicated by regression of the lymphadenopathy and resolution of the hypercalcaemia.

Twelve days after the CHOP chemotherapy, her serum sodium concentration had fallen to $129 \mathrm{mmol} / \mathrm{l}$ (normal range 134-145 $\mathrm{mmol} / \mathrm{l})$. The patient remained euvolaemic and asymptomatic and no nausea or vomiting had been reported after the chemotherapy. The hospital chart documented that the daily urinary output ranged from 1.5 to 2 litres. The urinary osmolality was 268 to $302 \mathrm{mOsm} / \mathrm{kg}$ as compared to her serum osmolality of $255 \mathrm{mOsm} / \mathrm{kg}$. Other laboratory studies revealed a serum potassium level of $4.1 \mathrm{mmol} / \mathrm{l}$ (normal range 3.8-5.4 mmol/l), random glucose 8.3 $\mathrm{mmol} / \mathrm{l}$, serum creatinine $99 \mathrm{\mu mol} / \mathrm{l}$, and a urinary sodium concentration of 40 $\mathrm{mmol} / \mathrm{l}$. Both thyroid function and adrenal assessment were normal and there were no pulmonary or mediastinal lesions seen on a chest radiograph.

\section{QUESTIONS}

(1) What is the best explanation for her biochemical picture?

(2) List the possible causes.

(3) What is the management?

Postgrad Med J 2003;79:61

\section{Authors' affiliations}

\section{K M Chow, C C Szeto, Department of}

Medicine and Therapeutics, Chinese University of Hong Kong, Shatin, Hong Kong, SAR, China

Correspondence to: $\operatorname{Dr}$ C C Szeto, Department of Medicine and Therapeutics, Chinese University of Hong Kong, Prince of Wales Hospital, Shatin, Hong Kong ccszeto@cuhk.edu.hk

Submitted 9 August 2002

Accepted 14 October 2002

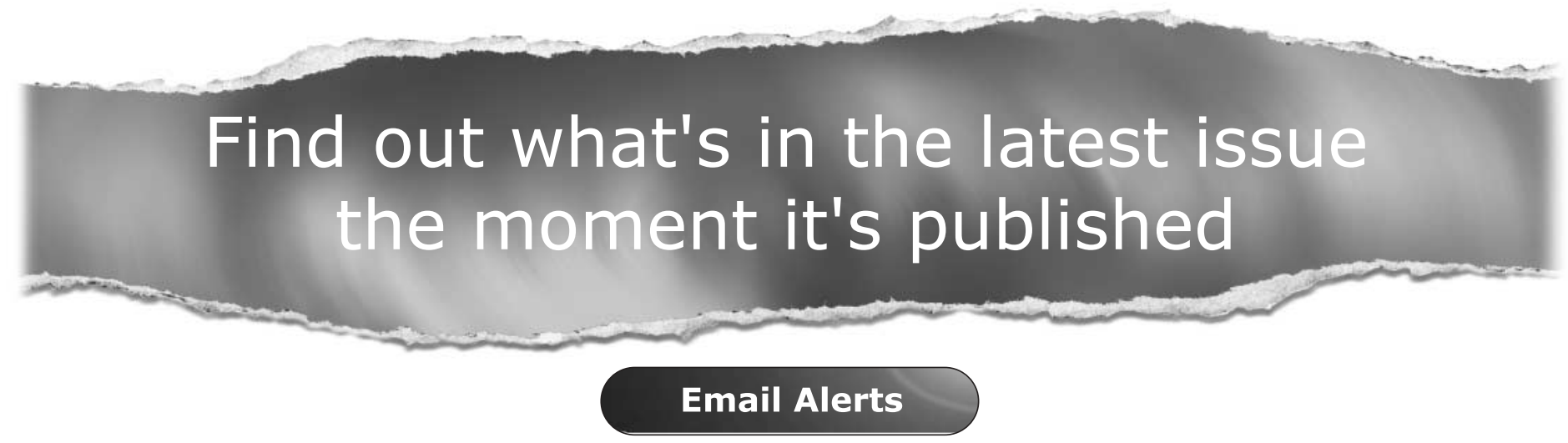

Sign up to receive the table of contents by email every month. You can select from three alerts: Table of Contents (full), TOC Awareness (notice only); Postgraduate Medical Journal related announcements. 
Pulmonary nodules

\section{Multiple pulmonary nodules: diagnosis in an young afebrile patient}

\section{K S Sodhi, M Kang, M Gulati, S Suri}

Answers on $p 64$.

\begin{abstract}
A 22 year old women presented with complaints of vague pain in the chest for three months and cough with expectoration for six days before admission. On examination, she was afebrile and non-dyspnoeic. Her pulse rate, respiration rate, and blood pressure were within normal limits. Her white cell count was only mildly raised. She had a normal haemoglobin concentration and erythrocyte sedimentation rate. Mantoux test was negative.

Chest radiography (fig 1) and computed tomography (fig 2) showed bilateral, multiple, well defined lung parenchymal nodules, randomly distributed throughout both lung fields. An air crescent was also seen in one of the nodules in the right lower lobe (fig 2B). Casoni's test was done later, which was positive. No mediastinal or hilar lymphadenopathy and no pleural or pericardial effusion was seen.
\end{abstract}

\section{QUESTIONS}

(1) What is the diagnosis?

(2) What is the differential diagnosis? formed? crescent sign? cent sign?

Postgrad Med J 2003;79:62

(3) How does this condition present?

(4) What other tests should be per-

(5) What is the pathogenesis of the

(6) What are other causes of the cres-

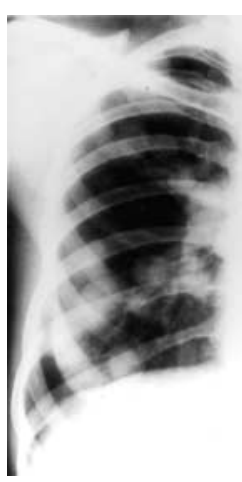

Figure 1 Chest radiograph of patient
Authors' affiliations

K S Sodhi, M Kang, M Gulati, S Suri,

Department of Radiodiagnosis, Postgraduate Institute of Medical Education and Research,

Chandigarh, India

Correspondence to: Dr Kushaljit Singh Sodhi, Department of Radiodiagnosis, Postgraduate Institute of Medical Education and Research (PGIMER), Chandigarh-160012, India; Sodhiks@rediffmail.com

Submitted 11 June 2002

Accepted 27 August 2002

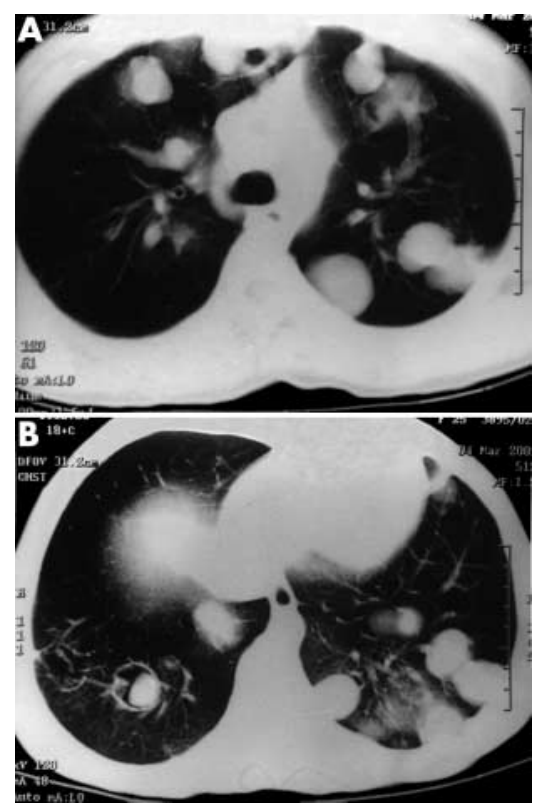

Figure 2 (A) Computed tomogram showing multiple pulmonary nodules. (B) Crescent sign is seen in the right lower lobe nodule. 